An Experience Sampling Study of Expressing Affect, Daily Affective WellBeing, Relationship Quality and Perceived Performance

\author{
Kevin Daniels ${ }^{1}{ }^{*}$, Jane Glover ${ }^{2}$, and Nadine Mellor ${ }^{3}$ \\ ${ }^{1}$ University of East Anglia \\ ${ }^{2}$ Loughborough University \\ ${ }^{3}$ Health and Safety Laboratory
}

*Correspondence to Kevin Daniels, Norwich Business School, University of East Anglia, Norwich, Norfolk, NR4 7TJ, United Kingdom. Email: kevin.daniels@uea.ac.uk.

Acknowledgments: We are grateful to Karina Nielsen, Ana Sanz Vergel and Olga Tregaskis for comments on earlier drafts of this manuscript. 


\title{
An Experience Sampling Study of Expressing Affect, Daily Affective Well- Being, Relationship Quality and Perceived Performance
}

\begin{abstract}
Few studies have directly examined the processes through which workers use job resources, such as job control and social support, to regulate affect. We focused on affective expression, which is a specific form of affect regulation. We investigated the extent to which workers used both job control and social support to express affect. Thirty nine call center workers provided data up to four times a day over five consecutive working days (number of observations $=272$ ). Executing job control in order to allow workers to express affect was related to using social support to express affect. Workers' understanding of their personal goals mediated relationships between using social support to express affect and four outcomes (negative affect, positive affect, perceived performance, and quality of workplace relationships). Perceived empathy mediated relationships between using social support to express affect and three outcomes (negative affect, positive affect, and quality of workplace relationships). The findings indicated that a) one job resource can be used to facilitate using another job resource for affect regulation and b) different job resources may play different roles in conferring benefits from affective expression.
\end{abstract}

(183 words) 


\section{Practitioner points}

- Jobs cannot be treated as static entities with fixed characteristics. Rather workers will use resources embedded in job design for specific purposes.

- Job redesign interventions intended to enhance affective well-being need to take account of the social and cognitive processes that mediate the relationship between work and affective well-being.

- Job redesign interventions need to integrate information about dynamic processes in which use of one job resource can enable use of another job resource. 
Two influential resource-based models of job design are the Job Demands-Resources model (JD-R, Bakker \& Demerouti, 2007; Demerouti, Bakker, Nachreiner, \& Schaufeli, 2001) and the Demand-Control-Support Model (DCSM, Karasek \& Theorell, 1990). Both models indicate that job resources are beneficial because job resources allow workers to selfregulate any adverse impact of work. Although many studies demonstrate associations between job resources and a range of beneficial outcomes such as well-being (e.g., Häusser, Mojzisch, Niesel, \& Schulz-Hardt, 2010), few studies have directly examined the processes that underpin the relationships between job resources and beneficial outcomes (Van den Broeck, Vansteenkiste, De Witte, \& Lens, 2008). Instead, many studies infer that job resources facilitate self-regulation from results that demonstrate workers with higher levels of resources also have better well-being (Daniels, Glover, Beesley, Wimalasiri, Cohen, Cheyne, \& Hislop, 2013a). However, simply assessing the presence or absence of job resources provides no information on whether the benefits of job resources derive from workers actively using job resources for self-regulatory functions.

Self-regulation concerns how humans control their behaviors and inner states. Selfregulation encompasses conscious and non-conscious processes, and includes regulation of affective states (Vohs \& Baumeister, 2004). In the present study, we focus on the use of job resources for a specific form of affect regulation: affective expression. In line with DCSM, we focus on the use of two resources (job control, social support) for affective expression.

Our study makes two contributions. Our first contribution is to examine whether using one job resource, specifically job control, to express affect enables workers to use another job resource, social support, to express affect. To date, research on daily job resources has tended to concentrate on relationships between job and personal resources (e.g., Xanthopoulou, Bakker, Demerouti, \& Schaufeli, 2009), rather than relationships between different job resources. Examining how workers use one job resource to enable use of another resource 
contributes to debates about how workers initiate changes to the content and experience of their work (Grant \& Parker, 2009; Wrzesniewski \& Dutton, 2001).

Our second contribution is to examine whether the relationships between using social support to express affect and beneficial outcomes (affective well-being, perceived job performance, and relationship quality) is mediated by specific processes. We focus on two mediators related to personal goal achievement and perceived empathy. By examining goal related processes, we elaborate on the principle that job resources enable achievement of personal goals (Demerouti et al., 2001). In addition and to our knowledge, resource based models of job design have not yet explicitly considered empathy as a mediator of job resources on well-being and other outcomes. This is an important omission because the fulfillment of social needs is thought to underpin some of the benefits of job resources (Bakker \& Demerouti, 2007; Bakker, Demerouti, \& Sanz-Vergel, 2014).

\section{Affective well-being and expressing affect}

Affective well-being reflects the frequent experience of positive affects (e.g., enthusiasm) and infrequent experience of negative affects (e.g., anxiety) and is among the most important, if not the most important, indicator of the more general construct of psychological well-being (Diener \& Larsen, 1993). Affective well-being varies within the working day and is influenced by events that occur during the working day (Weiss \& Cropanzano, 1996). Workers attempt to self-regulate their affective responses to events. Affective regulation is also dynamic and varies within the day (Todd, Tennen, Carney, Armeli, \& Affleck, 2004). Therefore, studying within-day processes as they occur captures accurately the processes surrounding affect, workplace events, and affect regulation (Todd et al., 2004).

One form of affective self-regulation is affective expression (Baker \& Berenbaum, 2007; Gross \& Thompson, 2007; Gross, 2008; Stanton \& Franz, 1999; Parkinson \& Totterdell, 1999). Affective expression involves displaying and venting affect, and can include verbal and non- 
verbal displays (Clark \& Finkel, 2004). Workers may choose to express affect in a number of ways and affective displays need not be made in the presence of others (e.g., swearing in one's office after receiving a call from a rude colleague, laughing at a humorous email). Indeed, expressing affect to others at work may be considered inappropriate as it violates organizational display norms, especially those concerned with rationality, and/or considered as indicative of incompetence (Ashforth \& Humphrey, 1995). So that workers conform to organizationally sanctioned display rules, we consider that workers will express affect in circumstances in which the display rules do not apply, and so workers will seek out such circumstances when they wish to express (e.g., appropriate locations, times, people to express in front of). Specifically, relationships between affective well-being and affect regulation strategies may depend on how workers use the job resources embedded in their work environment (Daniels, Beesley, Wimalasiri, \& Cheyne, 2013b).

Job resources and worker agency in affective expression

In JD-R, job resources are beneficial for well-being for two reasons. First, job resources have motivational properties (Bakker \& Demerouti, 2007) because job resources satisfy psychological needs (Van den Broeck et al., 2008) and enable achievement of personal goals (Demerouti et al., 2007). Second, job resources enable workers to self-regulate any adverse impact of work on well-being. Self-regulation is also embedded in DCSM (Karasek \& Theorell, 1990), which focuses on the job resources of job control and social support. Job control relates to the worker's authority to make decisions, including decisions on when and how to execute tasks (Karasek \& Theorell) and even some decisions relating to work objectives (Breaugh, 1985). Although skill use and job control were initially considered to be part of the same concept in DCSM, job control may be more important for well-being than skills use (Wall, Jackson, Mullarkey, \& Parker, 1996). Social support at work is characterized by receiving help from supervisors and coworkers (Karasek \& Theorell, 1990). 
Gorgievski, Halbesleben, and Bakker (2011) indicate that there are strong conceptual links between both JD-R and DCSM and the more general Conservation of Resources theory (COR, Hobfoll, 2002). Both JD-R and COR consider resources to enhance well-being because resources have intrinsic value. Because resources have intrinsic value, people are motivated to accumulate resources. Through the accumulation of resources, people can develop resource caravans of inter-dependent resources. Similar to JD-R and DCSM, COR indicates that resources also enhance self-regulation. However, COR does indicate that using resources for self-regulation deteriorates resources. For example, workers who decide to reschedule work tasks to allow them some time to express affect may expend cognitive resources in finding the best new schedule for the tasks. Nevertheless, COR indicates that self-regulatory efforts are successful if resources are restored or increased over the longer term. For example, self-regulation may expend energy in the short-term, but allow recuperation and restoration of energy in the longer term. Moreover, because resources are substitutable, people may be willing to expend one or more resources (e.g., energy by working long hours) to gain other resources (e.g., enhanced remuneration).

In the present study, we focus on the idea that job resources enable self-regulation. This idea is embedded in JD-R, DCSM, and COR. Following the JD-R, we consider that job resources can enable self-regulation that is oriented toward achieving goals. We concentrate on the resources of job control and social support, because these are important resources, embedded in an established model (DCSM), are widely researched in tests of the JD-R (Bakker et al., 2014), and represent a good starting point to develop more complex models (Van Veldhoven, Taris, de Jonge, \& Broersen, 2005). Moreover, models that draw on multiple resources, such as DCSM, are likely to have wider explanatory power than models that focus on a single resource (Hobfoll, 2002). From COR, we draw on the idea of resource 
caravans in which one job resource may be used to facilitate using another job resource. However, self-regulation involves worker agency in how job resources are used.

Whereas much research has assessed the presence or absence of job resources (e.g., Häusser et al., 2010), researchers have more recently examined how workers are proactive in shaping their work environment (Grant \& Parker, 2009). For example, research on 'job crafting' has examined worker-initiated changes to work so that workers can improve their working conditions (Tims, Bakker, \& Derks, 2013; Wrzesniewski \& Dutton, 2001). People may craft their jobs to make work more interesting or meaningful (Wrzesniewski \& Dutton, 2001), to pursue personal vocational interests (Berg, Grant, \& Johnson, 2010), or develop job resources (Tims et al., 2013). Workers can craft their jobs either alone or in collaboration (Leana, Appelbaum, \& Sevchuk, 2009; Tims, Bakker, Derks, \& van Rhenen, in press). Crafting can take place over several weeks (Tims et al., 2013) or during the working day (Petrou, Demerouti, Peeters, Schaufeli, \& Hetland, 2012).

The notion that workers are proactive in shaping their work environment reflects a focus on workers' behavior in enacting their work environment and provides a basis for expecting that workers are proactive in using job resources for self-regulation. In this respect, it is possible to differentiate daily job crafting that builds resources from daily enactment of job resources for self-regulation (Daniels, 2006, 2011). Studies have already examined some forms of self-regulation during the working day such as studies on recovery activities during work breaks (Trougakos, Beal, Green, \& Weiss, 2008; Trougakos, Hideg, Cheng, \& Beal, in press) and studies focused on enactment of job resources for problem-solving (Daniels, Boocock, Glover, Hartley, \& Holland, 2009; Daniels, Wimalasiri, Cheyne, \& Story, 2011; Daniels et al., 2013b).

The idea that workers are active in enacting aspects of the work environment is apparent in the distinction between behavior and the function of that behavior (cf. Skinner, 
Edge, Altman, \& Sherwood, 2003). In respect of affective self-regulation, function is the target of affective self-regulation. Examples of affective self-regulation functions are expressing affect and modifying the event that influences affect (Gross, 2008). Affective self-regulation behavior refers to those actions that enable the function of affective self-regulation to have its desired effect. As an example, a worker may choose to express affect (function) by talking to colleagues (behavior).

Some behaviors used for affective expression are related to the job resources of social support and job control (Daniels, Beesley, Cheyne, \& Wimalasiri, 2008; Daniels et al., 2013b). An example of a behavior to elicit the resource of social support is talking to others to express affect. To illustrate, a worker may visit a trusted colleague's office to express affect to that colleague. By talking to others, workers may draw on supportive relationships with others to show, state, and explain their feelings about events to supportive coworkers. An example of a behavior to execute the resource of job control is rescheduling activities to allow private venting. To illustrate, a worker may exert control over work schedules to take an unscheduled break immediately after a bitter argument with a regular customer to spend a few minutes crying privately in an unoccupied meeting room. As well as allowing private venting, rescheduling activities with the intention to express affect may allow workers the time and scope to choose other ways to express affect (through for example taking unscheduled breaks with coworkers).

Daniels et al. (2009) have labeled the combinations of affective expression and enacted job resources as 'changing aspects of work activities to express affect' (for using job control to express affect, abbreviated to CHA-EA) and 'talking to others to express affect' (for using social support to express affect, abbreviated to TAL-EA). To precisely identify the processes through which job resources have their effects, it is important to operationalize and assess such combinations of affective expression and enacted job resources. Simply assessing levels of job 
control or social support provides no information on how job resources are used, and for which affect regulation functions (e.g., expressing affect, situation modification). As such, linear effects of job resources and interactions with job demands on outcomes also provide no information on how job resources are used to accrue benefits for workers (Daniels et al., 2009). Similarly, simply assessing the extent to which an affect regulation function is deployed provides no information about how workers use job resources to ensure the function confers benefits.

It might be argued that measures that assess the use of job control or social support could be correlated with measures of affective expression, and measures of affective expression could be correlated with various outcomes (e.g., perceived empathy). However, demonstrating such mediated relationships still provides no precise information on how affective expression confers its benefits. For example, suppose there is a correlation between using job control and affective expression and a correlation between affective expression and an outcome variable. The correlation between using job control and affective expression may indicate that job control allows an individual to express affect. Alternatively the correlation may indicate that job control allows an individual the latitude to seek out others to express affect to. The correlation between affective expression and the outcome may indicate any behavior that allows affective expression confers benefits. An alternative explanation would be that only those behaviors used in the majority of situations to express affect are beneficial, and leaves open the possibility that some behaviors used infrequently to express affect may confer no benefits or even be harmful. Directly assessing whether job resources are used for a specific function (e.g., through measures of TALEA and CHA-EA) provides more precise information.

\section{Job control and affective expression}

Executing job control to express affect or 'changing aspects of work activities to express affect' may allow workers to self-regulate without involving others. In the examples given earlier, 'changing aspects of work activities to express affect' may allow workers to 
take a break from work tasks to express affect when it is most beneficial to do so, such as immediately after an affectively charged event (cf. Karasek \& Theorell, 1990) or to allow the time to find a place to vent in private. However, another function may be to allow workers the time, space, and freedom to seek out supportive persons to express affect to. Thus, there may be a co-dependency between job resources, such that using one resource (job control) enables use of another resource (social support) to achieve a self-regulatory function (affective expression). There are two reasons for this proposition.

The first reason is theoretical. As previously described, COR indicates that people are motivated to foster resources and resources tend to co-occur in caravans. Although selfregulation can lead to deterioration of resources, people may decide to expend resources in order to utilize other resources that may be more effective for self-regulation (Hobfoll, 2002). Therefore, it is possible that workers may use one job resource in order to use another job resource. The second reason is related to the specific proposition that 'changing aspects of work activities to express affect' might enable 'talking to others to express affect'. There is evidence that: job control may lead to workers to seek resources to offset the impact of demanding situations (Petrou et al., 2012); to seek support for problem-solving (Daniels et al., 2013a); and to spend discretionary time with coworkers (Oldham \& Rotchford, 1983). Therefore:

Hypothesis 1: 'Changing aspects of work activities to express affect' (CHA-EA) will be positively associated with 'talking to others to express affect' (TAL-EA).

Benefits of affective expression through social sharing

Rimé $(2007,2009)$ contends that it is the process of expressing affect to others rather than private venting that influences affective well-being. Because affective displays can reveal information to others about goals and intentions (Côté, 2005; Graham, Huang, Clark, \& Helgeson, 2008; Van Kleef, 2009), any impact of affective expression on affect might be 
mediated by goal related as well as social processes (Fischer \& Manstead, 2008; Rimé, 2007, 2009). These processes may apply regardless of whether positive or negative affect is expressed (Fischer \& Manstead, 2008; Rimé, 2009).

Expressing affect through talking to others can enhance an individuals' understanding of their goals through sensemaking (Pennebaker, 1989; Rimé, Philippot, Boca, \& Mesquita, 1992). Sensemaking is a process focused on deriving meaning from situations and often takes places through social interaction (Weick, 1995). To express affect in conversation with others, individuals construct a narrative to explain the events that led to the affect and how those events have impacted on individuals' goals. In so doing, the focal individual has to ensure the narrative is coherent. Therefore, the act of expressing affect through talking to others enables individuals to: re-examine and re-interpret the event and its implications; understand threatening or confusing aspects of the experience; and gain feedback from others about future plans and strategies for attaining goals (Lepore, Ragan, \& Jones, 2000). In turn, this may enable people to refine or change their strategies for achieving goals or provide information, through feedback, that current strategies are worth persisting with, and therefore aid progress towards goals (Locke \& Latham, 2002). Affective well-being is influenced by perceptions of goal progress, such that perceptions of progress towards attaining goals is inversely associated with negative affect and associated with positive affect (e.g., Carver \& Scheier, 1990). Moreover, because work performance is a salient work goal (Beal, Weiss, Barros, \& MacDermid, 2005) and attention is directed toward salient goals (Locke \& Latham, 2002), we expect individuals to process information about their perceived work performance more readily than goals less proximal to daily work activities (e.g., social relationship goals which can be pursued outside of work and therefore may not be salient during work). Therefore: 
Hypothesis 2: The associations between 'talking to others to express affect' (TAL-EA) and a) negative affect, $b$ ) positive affect, and c) perceived performance will be mediated by understanding personal goals.

Expressing affect to others may enhance empathy (Rimé, 2009). Empathy occurs when another recognizes the expressor's affective state and identifies with the expressor's perspective on the reasons for that affective state (De Waal, 2008; Eisenberg, 2000). Expressing affect conveys information about the expressor's affective states, intentions, attitudes, and goals (Côté, 2005; Graham et al., 2008; Van Kleef, 2009), and may help socially validate and legitimize the affects experienced (Coupland, Brown, Humphreys, \& Daniels, 2008). In turn, through feedback from others, the expressor may experience empathy because the expressor perceives others understand the expressor's affective state and reasons for that affective state.

Expressing affect to another person signals trust in the other person as something personal is revealed about goals and intentions (Graham et al., 2008; Mauss, Shallcross, Troy, John, Ferrer, Wilhelm, \& Gross, 2011). Empathy indicates that trust is well-placed and provides positive feedback on the choice of person to express to and the quality of the relationship with that person. Perceiving empathy may also increase affection for the person providing empathy (Rimé, 2009). In turn, this may enhance the quality of the relationship further. Moreover, because expressing affect to another motivates the other person also to talk about his/her affective experiences (Curci \& Bellelli, 2004), expressing affect to another can lead to reciprocation cycles in which people reveal affective information to each other. Such reciprocation cycles may further enhance empathy and social bonds (Rimé, 2009).

Because attaining and maintaining secure and supportive relationships with others are fundamental goals (Ryan, 1995) and empathy is a signal of relationship quality, we also expect perceived empathy to be related to affective well-being as well as relationship quality. 
Hypothesis 3: The associations between 'talking to others to express affect' (TAL-EA) and a) relationship quality, $b$ ) negative affect, and c) positive affect will be mediated by perceived empathy.

Hypothesis 1 implies a relationship between 'changing aspects of work activities to express affect' and 'talking to others to express affect', and Hypotheses 2 and 3 imply relationships between 'talking to others to express affect' and understanding personal goals and perceived empathy. We may therefore expect that workers who 'change aspects of work activities to express affect' may do so to enable them to 'talk to others to express affect' which in turn may enhance understanding of personal goals and perceived empathy. Therefore, by extension of Hypotheses 1, 2, and 3:

Hypothesis 4: There will be an indirect effect between 'changing aspects of work activities to express affect' (CHA-EA) and a) understanding personal goals and b) perceived empathy through 'talking to others to express affect' (TAL-EA).

The present study

We used an experience sampling methodology (ESM) to collect data several times a day because affect regulation is a dynamic process (Todd et al., 2004) and job resources have dynamic components (Daniels, 2006; Ilies, Dimotakis, \& De Pater, 2010; Xanthopoulou et al., 2009). Recall bias was minimized because assessments were made over a limited time frame. We controlled for a range of factors: the type of the affective events experienced and the type of the affect elicited by the events; and values of each criterion and independent variable assessed in the preceding measurement occasion and on the same day. We were also able to evaluate whether non-measured variables could account for the observed relationships, and therefore whether the causal direction implied in the hypotheses was more plausible than alternatives. We focused on the major affective aspects of well-being at work 
(Warr, 2007), namely the anxiety component of negative affect and the motivated hedonic component of positive affect.

Because constructing a narrative to explain affect enables individuals to clarify their own goals and how to reach those goals (Austenfeld \& Stanton, 2004), we expected expressing affect to others to enhance understanding of personal goals and perceived empathy regardless of whether salient events elicited unpleasant or pleasant affect (Gable, Reis, Impett, \& Asher, 2004; Ilies, Keeney, \& Scott, 2011; Rimé, 2007, 2009). Nevertheless, we examined interactions between the affective valence of events experienced and the affective expression variables.

\section{Methods}

\section{Sample and procedure}

Participants were 39 managers and administrators at a call center for a government agency. The average age of the sample was 39.41 years $(S D=10.24)$. Twenty of the sample were male. On average, the sample worked 36.41 hours per week $(S D=6.40)$. Twenty five of the sample occupied administrative positions. Data were collected using personal digital assistants (PDAs). In the week preceding data collection, we checked that participants were able to operate the PDAs and could comprehend the items used in the assessments. The PDAs' alarm signaled when the questionnaire was to be completed (10.30 a.m., 12.30 p.m., 2.30 p.m., and 4.30 p.m.) on each day for one working week (Monday to Friday).

Participants provided data on 461 occasions. After taking into account known absences (e.g., scheduled leave), the average individual compliance rate was $70 \%$ (range $21 \%$ to $100 \%$ ). Our main analyses were conducted with control variables from the preceding measurement occasion on the same day. Assessing variables from the preceding measurement occasion increases internal validity by allowing us to assess whether changes in the independent/mediator variables are related to changes in the criterion variables. However, controlling for variables from the preceding measurement occasion on the same day precludes using data from the first 
measurement occasion of each day as criterion variables. In the present study, this reduced the number of useable observations in the analyses to 272 from the 39 participants.

\section{Measures}

Scores for all multi-item scales were calculated by summing the items and dividing by the number of items in the scale. The reliabilities (Cronbach's alpha) and inter-item correlations reported in the remainder of this section are based on hourly data.

Affective events. To assess the previous hour's most salient affective event, participants were asked "In the past hour, what kind of event has had the biggest impact on how you think or feel about work?". Participants were given the following options "conflict with another person" (endorsed on $6.9 \%$ of occasions), "pleasant social interaction" $(26.5 \%)$, "barriers to performing tasks" (21.5\%), "receiving help" (5.6\%), "doing difficult work" (18.4\%), and "other" $(21.0 \%)$. In the analyses, dummy codes represented the categories of events, with "other" as the reference category.

Participants were then asked "What was your main feeling about this event?". Participants were given the options "anxious" (endorsed on $10.0 \%$ of occasions), "sad" (1.3\%), "frustrated" (31.2\%), "happy" (27.3\%), "motivated" (13.9\%), and "other" (16.3\%). Dummy codes represented whether participants experienced an unpleasant affect $(=1)$, pleasant affect $(=1)$, with "other" as the reference category.

Affective expression. CHA-EA and TAL-EA were assessed with two items each. Ratings were made on a 6-point fully anchored scale $(1=$ not at all, $6=$ to a large extent $)$. An example for CHA-EA is "In the past hour, did you change the order in which you normally do work tasks to get your emotions off your chest?" An example item for TAL-EA is "In the past hour, did you confide in other people at work to get your emotions off your chest?". These items link the specific behaviors of eliciting support (e.g., "confiding in other people") 
and executing job control ("did you change the order in which you normally do work tasks") to the specific purpose of expressing affect.

Daniels et al. (2008, 2009; 2011; 2013b) provide evidence for reliability and validity of these scales. Daniels et al. (2009) reported a number of checks that the items are interpretable. In the present study, we checked the structure of the items using multilevel confirmatory factor analysis (ML-CFA). A one factor solution did not fit the data (Comparative Fit Index $\{\mathrm{CFI}\}=.73$, Root Mean Square Error of Approximation $\{$ RMSEA $\}$ $=.23)$. ML-CFA indicated an acceptable fit for the hypothesized two factor solution $(\mathrm{CFI}=$ 1.00, RMSEA = .02). Freely estimated factor loadings were all in the hypothesized direction for within- and between-parts of the model $(p<.01)$. Reliability for both scales was acceptable (CHA-EA $\alpha=.82$, inter-item $r=.69$; TAL-EA $\alpha=.88$, inter-item $r=.79$ ).

Understanding personal goals, perceived empathy, perceived performance, and relationship quality. Understanding personal goals, perceived empathy, perceived work performance, and relationship quality were each assessed by two-item scales. Items were rated in a 5-point scale $(1=$ not at all, 5= very much so $)$. Items are: "In the past hour, have you felt that you have a better understanding of how to deal with obstacles to your personal goals?" and "In the past hour, have you felt that you have a better understanding of what you want to achieve at work?" (understanding personal goals); "In the past hour, have you felt that others understand your feelings about things?" and "In the past hour, have you felt that others can see things from your point of view?" (perceived empathy); "Have you been able to perform your job well in the past hour?" and "Have you been able to work to your full potential in the past hour?" (perceived performance); "In the past hour, have you felt that you have good relations with others at work?" and "In the past hour, have you felt part of a strong team?" (relationship quality). The items were relevant to the sample, given the goal-directed character of human nature (understanding personal goals, Carver \& Scheier, 1990), that 
performance is a salient work goal (perceived performance, Beal et al., 2005), participants worked in open plan offices and had regular contact with colleagues during the working day (perceived empathy and addressing relationship quality).

ML-CFA indicated the hypothesized four factor solution had an acceptable fit to the data $(\mathrm{CFI}=0.98, \mathrm{RMSEA}=.06)$. Freely estimated factor loadings were all in the hypothesized direction for within- and between-parts of the model $(p<.01)$. A series of three factor solutions was examined, in which items from each scale were set to load with items from another scale (e.g., perceived empathy and relationship quality items loaded on the same factor, understanding personal goals and perceived performance items loaded on their hypothesized factors). All possible combinations were tested in these three factor models. None of the three factor models fitted the data as well as the four factor model $(\mathrm{CFI} \leq .93$, RMSEA $\geq .08$ ). Reliability for the scales was acceptable (understanding personal goals $\alpha=$ .84 , inter-item $r=.72$; perceived empathy $\alpha=.86$, inter-item $r=.75$; perceived work performance $\alpha=.90$, inter-item $r=.83$; and relationship quality $\alpha=.78$, inter-item $r=.66$ ).

End of hour affective well-being. Participants were asked to rate how they felt at that moment in time. Negative affect (NA) was assessed with the items "anxious" and "worried". Positive affect (PA) was assessed with the items "motivated" and "enthusiastic". These are valid indicators of the anxiety component of NA and motivated hedonic component of PA in work contexts (Daniels, 2000). Items were rated on a 5-point scale $(1=$ not at all, $5=$ very). (NA $\alpha=.85$, inter-item $r=.74$; PA $\alpha=.96$, inter-item $r=.92$. )

By assessing momentary affective well-being at the end of each hour, we decoupled affect as a criterion variable from the affect elicited by the hour's most salient event. To check that the end of hour affective well-being items reflected different constructs from the affects elicited by the hour's most salient event, we conducted ML-CFAs. The ML-CFAs included the end of hour NA and PA items and two dummy codes representing whether the 
hour's most salient event had elicited an unpleasant or pleasant affect (both dummies were treated as categorical variables). In the best fitting model, the end of hour NA and PA items loaded on their hypothesized factors and the event dummies were freely correlated with the factors $(\mathrm{CFI}=.99, \mathrm{RMSEA}=.04)$. Freely estimated loadings were in the hypothesized direction for within- and between-parts of the model $(p<.02)$. Model fit did not meet conventional thresholds (Byrne, 2012) in models in which end of hour NA items and the event dummy for unpleasant affect loaded on the same factor $(\mathrm{CFI}=.93$, RMSEA $=.10)$ and in which end of hour PA items and the event dummy for pleasant affect loaded on the same factor $(\mathrm{CFI}=.88, \mathrm{RMSEA}=.13)$.

Analysis

We analyzed the data using structural equation modeling. The data had a nested structure with observations nested within individuals. On average, some $48 \%$ of the variance in the criterion variables could be attributed to within-person variations over the course of the week (range $30 \%$ for end of hour PA to $66 \%$ for perceived performance). We centered each criterion and predictor variable at each participant's mean because we were interested in within-person differences as well as to account for the multilevel structure of the data, stable between person differences, and dependencies in the data. Centering criterion variables enables analysis to proceed as a single level model since all between-person variance in the criterion variables are removed (cf. Beck, 2008). An analysis of the intra class correlations (ICCs) of the centered variables indicated that centering had removed dependencies in the data due to stable betweenperson variation (all ICCs < .0003; Muthén, 1997). ${ }^{1}$ We used robust standard errors because of non-normality in the data (Byrne, 2012) and because robust standard errors are unaffected by non-independence of observations as occurs with experience sampling data (Satorra, 1992). For each criterion variable, we controlled for type of salient affective event, valence of affect elicited by the salient affective event, and all criterion and independent variables assessed in the occasion 
preceding the focal hour on the same day. Time of day and day of week did not account for significant amounts of variance in any of the substantive independent or criterion variables. Therefore, we did not control for time of day or day of week.

We evaluated three different structural equation models. As well as the $\chi^{2}, \mathrm{CFI}$ and RMSEA, we also used Akaike's information criterion (AIC) to compare models. Lower values of AIC indicate better fit. In each model, residuals of perceived performance, relationship quality, end of hour NA, and PA were allowed to correlate. Residuals of understanding personal goals and perceived empathy were also allowed to correlate. Model 1 was a fully saturated model, in which PA, NA, perceived performance, and relationship quality were regressed on understanding personal goals, perceived empathy, TAL-EA, and CHA-EA, and understanding personal goals and perceived empathy were regressed onto TAL-EA and CHA-EA. Model 2 was an indirect effects only model: Model 2 was the same as Model 1, excepting paths from TAL-EA and CHA-EA to each of PA, NA, perceived performance, and relationship quality were all set to zero. Model 3 was the same as Model 2, excepting the paths from CHA-EA to understanding personal goals and perceived empathy were set to zero.

To test the indirect effects stated in the Hypotheses, we first evaluated the significance of paths from CHA-EA to TAL-EA, TAL-EA to each of the hypothesized mediators and from each of the mediators to its criterion variables. We next evaluated the significance of the indirect effects of CHA-EA and TAL-EA using two techniques. First, we used bias corrected bootstrapping methods (Edwards \& Lambert, 2007). Although bootstrapping is the preferred way of evaluating indirect effects, there is no agreed procedure for bootstrapping data with a nested structure (Preacher \& Selig, 2012). Therefore, we also used the prodclin-r program, which uses the distribution of the product of two normally distributed random variables to 
compute confidence intervals for indirect effects (MacKinnon, Fritz, Williams, \& Lockwood, 2007).

To determine whether the causal direction implied in the Hypotheses was the most plausible, we used an instrumental variable technique (Shaver, 2005). This technique allowed us to determine whether residuals in the criterion variables were related to the criterion variables' hypothesized predictors. If relationships with residuals and hypothesized predictors were found to differ from zero, there would be evidence that unmeasured variables could account for the observed relationships (e.g., method variance, changes in cognitive processes associated with changes in affect). We used Model 3 as a basis for identifying the instrumental variable models. If required for identification purposes, further constraints were made, subject to the requirement that the constraints did not result in model fit that failed to meet conventional thresholds (i.e., CFI < .95, RMSEA > .08; Byrne, 2012). As a further check on the results, we also evaluated the relationships using grand mean centering of variables and trait analogues of the ESM variables assessed prior to the ESM period as control variables rather than lagged assessments of the ESM variables (details available from the authors). We also evaluated interactions between the valence of the hour's most salient affective event and the affective expression variables on all the criterion variables.

\section{Results}

Table 1 shows means, standard deviations, reliabilities, and within-person correlations. Within-person correlations are shown as these are the basis of the inferential analyses. Table 1 shows preliminary support for Hypotheses 1, 2, 3 and 4, in that all the associations implied in the Hypotheses were in the hypothesized direction and significant (range of $r$ 's $|.11|$ to $|.46|$, all $p<.05$ ). Neither TAL-EA nor CHA-EA were related to events reported to cause unpleasant or pleasant affect (range of $r$ 's -.02 to $.08, n s$ ), indicating 
affective expression is equally likely for events reported to cause unpleasant affect as it is for events reported to cause pleasant affect.

INSERT TABLE 1

Compared to the fully saturated Model $1\left(\chi^{2}=0, \mathrm{CFI}=1.00, \mathrm{RMSEA}=0.00, \mathrm{AIC}=\right.$ 10172.04), both Model $2\left(\Delta \chi^{2}=9.46, \mathrm{df}=8, n s ; \mathrm{CFI}=1.00 ; \mathrm{RMSEA}=0.03, \mathrm{AIC}=\right.$ 10168.67) and Model $3\left(\Delta \chi^{2}=9.92, \mathrm{df}=10, n s ; \mathrm{CFI}=1.00 ; \mathrm{RMSEA}=0.00, \mathrm{AIC}=\right.$ 10164.86) had acceptable fit. Because Model 2 and Model 3 did not differ $\left(\Delta \chi^{2}=0.46, \mathrm{df}=2\right.$, $n s)$ and Model 3 is more parsimonious and had the lowest AIC, we accepted Model 3 as the best model overall. Figure 1 summarizes Model 3.

\section{INSERT FIGURE 1}

Figure 1 shows that CHA-EA was related to TAL-EA $(B=0.56, p<.01)$, providing support for Hypothesis 1.

TAL-EA was related to understanding of goals $(B=0.08, p<.05)$. In turn, understanding personal goals was related to end of hour NA $(B=-0.23, p<.01)$, end of hour PA $(B=0.20, p<.01)$, and perceived performance $(B=0.32, p<.01)$. Together, these results provide support for Hypothesis 2. Further support for Hypothesis 2 is provided by the indirect effects. TAL-EA had indirect effects on end of hour NA $(-0.02, p<.05$ for bootstrapping and prodclin-r method, narrowest $95 \%$ confidence interval from the two methods $\{\mathrm{CI}\}-.04$ to $-.01)$, end of hour PA $(0.02, p=.05$ for bootstrapping and $p<.05$ for prodclin-r method, narrowest $95 \% \mathrm{CI} .01$ to .04$)$, and perceived performance $(0.03, p<.05$ for bootstrapping and prodclin-r method, narrowest $95 \%$ CI .01 to .06). Understanding personal goals was also related to relationship quality $(B=0.25, p<.01)$, and the indirect effect of TAL-EA on 
relationship quality though understanding personal goals was significant $(B=0.02, p<.05$ for bootstrapping and prodclin-r method, narrowest 95\% CI .01 to .05).

Figure 1 shows that TAL-EA was related to perceived empathy $(B=0.25, p<.01)$. Perceived empathy was related to end of hour NA $(B=-0.14, p<.05)$, end of hour PA $(B=$ $0.20, p<.01)$, and relationship quality $(B=0.18, p<.05)$. These results provide support for Hypothesis 3. The indirect effects also support Hypothesis 3. TAL-EA had indirect effects through perceived empathy on end of hour NA $(-0.04, p<.05$ for bootstrapping and prodclin$\mathrm{r}$ method, narrowest $95 \% \mathrm{CI}-.07$ to -.01$)$, end of hour PA $(0.05, p<.01$ for bootstrapping and prodclin-r method, narrowest $99 \%$ CI .01 to .10$)$, and relationship quality $(B=0.05, p<.01$ for bootstrapping and prodclin-r method, narrowest 99\% CI .01 to .09).

Because CHA-EA was related to TAL-EA, and TAL-EA was related to understanding personal goals and perceived empathy, there is support for Hypothesis 4. Analysis of the indirect effects provides further support for Hypothesis 4. CHA-EA has an indirect effect through TAL-EA on understanding personal goals $(B=0.05, p<.10$ for bootstrapping and $p$ $<.05$ for prodclin-r method, narrowest $95 \%$ CI .01 to .09) and perceived empathy $(B=0.14$, $p<.01$ for bootstrapping and prodclin-r method, narrowest $99 \%$ CI .07 to .22 ).

The instrumental variable models did not provide evidence that any of the paths shown in Figure 1 could plausibly be accounted for by unmeasured variables. Moreover, each of the relationships shown in Figure 1 was replicated in the fully saturated model (Model 1) $(p<.05)$. In Model 1, there was an inverse relationship between CHA-EA and perceived performance $(B=-0.16, p<.01)$, although there were no other unexpected relationships between the criterion variables and either CHA-EA or TAL-EA. This non-hypothesized relationship between CHA-EA and perceived performance should be interpreted with caution, because Model 1 did not provide better fit to the data than Model 3. 
It is implausible that end of hour NA, end of hour PA, perceived performance, and relationship quality are direct causes of TAL-EA for two reasons. First, Model 3 has no direct links between either CHA-EA or TAL-EA and end of hour NA, end of hour PA, perceived performance, and relationship quality. Second, there were no significant relationships between end of hour NA, end of hour PA, perceived performance, or relationship quality and TAL-EA in Model 1. Further support for the Hypotheses was provided by a version of Model 3 that used grand mean centering rather than group mean centering, and trait analogues of the variables as controls rather than lagged ESM variables. In this grand mean centered model, all of the direct and indirect relationships shown in Figure 1 were replicated $(p<.05){ }^{2}$

Finally, we ran a version of Model 1 in which all of the criterion variables were regressed on two-way interactions between the affective valence of the hour's most salient event and either TAL-EA or CHA-EA. All relationships shown in Figure 1 were replicated ( $p$ $<.05$ ). Although three interactions were significant (all $p<.01$ ), a comparison between models with and without interactions included indicated that the interactions did not make a significant difference to model fit $\left(\Delta \chi^{2}=26.80, \mathrm{df}=26, n s\right.$ : Model with interactions $\mathrm{CFI}=$ 1.00, $\mathrm{RMSEA}=0.00, \mathrm{AIC}=10973.49:$ Model without interactions $\mathrm{CFI}=1.00, \mathrm{RMSEA}=$ 0.00, $\mathrm{AIC}=10965.23)$.

\section{Discussion}

As indicated in the present study, job resources (job control) may be used in a dynamic and short-term way to allow benefits to accrue from using other job resources (social support) that are effective for specific affective self-regulation functions (affective expression). More generally, the results indicate that the processes through which workers enact and build job resources in their daily work may be based on interdependencies between job resources. Our findings build on JD-R (Bakker \& Demerouti, 2007; Demerouti et al., 2001), DCSM (Karasek \& Theorell, 1990), and COR (Hobfoll, 2002) by providing direct 
evidence showing that resources are used for self-regulation, and on the notion of resource caravans in COR by providing evidence that one job resource can be used to facilitate using another job resource. Further, the results build on JD-R by showing that goal related processes and empathy are two routes through which job resources enable self-regulation to have benefits.

We found support for all of the Hypotheses. We found that CHA-EA has a relationship with TAL-EA (Hypothesis 1). TAL-EA's relationships with affective well-being were mediated by understanding personal goals and perceived empathy (Hypotheses 2 and 3). TAL-EA's relationship with perceived performance was mediated by understanding personal goals (Hypothesis 2). Perceived empathy mediated the relationship between TAL-EA and relationship quality (Hypothesis 3). Unexpectedly, we found TAL-EA had an indirect relationship with relationship quality through understanding of personal goals. CHA-EA had an indirect effect through TAL-EA on understanding personal goals and perceived empathy (Hypothesis 4). There was some suggestion of an inverse relationship between CHA-EA and perceived performance.

Using job control to express affect may be beneficial if job control is used with the intention to express affect to supportive others. Evidence for this statement comes from the direct relationship between using job control to express affect and talking to others to express affect and indirect relationships with understanding personal goals and perceived empathy. Executing job control may enable an individual to choose to spend discretionary time with coworkers (Oldham \& Rotchford, 1983), and so job control may enable workers to choose the most suitable moment to take an unscheduled break (cf. Karasek \& Theorell, 1990) with coworkers to allow social sharing of affect. For example, a worker may use control over schedules to take an unscheduled break with a work friend immediately after receiving positive feedback from a supervisor. The worker may wish to express pleasure at the 
feedback to someone who would not be jealous or envious. Control over schedules may allow a worker enough time to find the right person to express affect to and the time to find an appropriate place to express affect to others (e.g., a place away from public workspaces, cf. Bamberger, 2009). To comply with organizational display rules (Ashforth \& Humphrey, 1993), it may be important for workers wishing to express affect to seek appropriate moments and spend time to find appropriate situations and persons. This is because the accuracy of others' inferences regarding the expresser may be impeded in situations when it is inappropriate to express affect (Van Kleef, 2009).

Our finding that using one job resource during the work day leads directly to using another job resource during the work day, which in turn leads to potential gains (understanding goals, empathy), is consistent with COR (Hobfoll, 2002). The present study and two other studies (Petrou et al., 2012; Daniels et al., 2013a) found inter-dependencies between daily job resources, such that using one job resource may lead to another resource to be used. Petrou et al. found that when daily demands were high, daily availability of job autonomy was associated with an increase in a composite measure of job resources that included items related to seeking advice and learning. Daniels et al. (2013a) found that job control could be used in ways that allowed social support to be used for problem-solving, and social support could be used in ways that allowed job control to be used for problem-solving. In the present study, we found that executing job control was associated with eliciting social support for the specific purpose of expressing affect.

The reasoning underpinning Hypothesis 1 and the statistical analyses in the present study suggest that for affective expression at least, the use of job control may influence the use of social support. However, Daniels et al. (2013a) found evidence of bidirectional relationships between using job control and social support in self-regulation. Therefore, codependencies between job resources may be influenced by the purposes for which job 
resources are used. Moreover, it is possible that using one resource to fulfill a self-regulatory function (e.g., eliciting social support for affective expression) enables the same resource or another resource to fulfill a second self-regulatory function (e.g., eliciting further support or executing job control for problem-solving).

The present study adds to other research that has indicated workers enact their work environment on a daily basis to self-regulate their experience of work (Daniels et al., 2009; 2013a; Petrou et al., 2012). However, research on workers being active in self-regulation essentially portrays workers as responding to external events. Workers also initiate changes through job crafting to improve their work environment (Wrzesniewski \& Dutton, 2001; Tims et al., 2013). Although the present study indicates interdependencies between how workers use different job resources, it is not yet clear whether self-regulation through enacting work characteristics can lead to longer-term proactive job crafting, whether job crafting over the longer term enables work environments to become more conducive to shortterm self-regulation, or whether self-regulation through enacting job characteristics and job crafting are independent of each other. Jobs may be designed or crafted to encourage prosocial behavior in incumbents (Grant, 2007). The present study also indicates that workers may enact the characteristics of their work to encourage prosocial acts (expressions of empathy) from others.

Talking to others to express affect was associated with understanding personal goals. Talking to others to express affect may enhance personal understanding of goals through the sensemaking required to provide a coherent narrative of affective events (Lepore et al, 2000; Pennebaker, 1989; Rimé et al., 1992; Weick, 1995), in turn leading to enhanced understanding of how to attain salient work goals, such as performance, and enhanced affective well-being (Carver $\&$ Scheier, 1990). We found an unexpected relationship between understanding personal goals and relationship quality. This unexpected relationship may be explained because developing 
and maintaining social relationships is a fundamental goal (Ryan, 1995), that may be especially salient in call center work given the physical proximity of coworkers. Therefore, enhancing understanding of personal goals may also contribute to developing strategies to attain social goals. Moreover, talking to others to express affect may enhance perceived empathy because expressing affect to others conveys information about the expressor (Côté, 2005; Graham et al., 2008; Van Kleef, 2009). In turn, empathy may enhance social relationships and enhance other forms of support (Rimé, 2009). Additionally, by signaling the quality of social relationships, empathy may enhance affective well-being.

In the present study, we examined hourly experiences in relation to talking to others to express affect and we found no evidence to suggest relationship quality may influence the extent of talking to others to express affect, personal understanding goals, or perceived empathy. However, it is possible that relationship quality influences the choice of person individuals choose to express affect to. It is also possible that over longer periods, relationship quality may play a role in that extent to which talking to others to express affect influences personal understanding of goals and perceived empathy.

We found no evidence that using job control to express affect, operationalized as 'changing aspects of work activities to express affect', had any direct relationships with either end of hour affective well-being or relationship quality. Because the analyses controlled for 'talking to others to express affect', the null findings suggest that executing job control to express affect in private (e.g., taking an unscheduled break in an unoccupied meeting room to shout or cry in private) may have no direct benefits for well-being or relationship quality. Changing aspects of work activities to express affect involves individuals taking decisions (e.g., rescheduling activities), and so the null relationships with affective well-being and relationship quality may reflect limitations in individual's capacity for affective regulation 
(Baumeister \& Alquist, 2009). Rather, talking to others to express affect may be a more efficient strategy that drains fewer cognitive resources.

We found some evidence that using job control to express affect had an inverse relationship with perceived performance, although the evidence is both non-hypothesized and found in a fully saturated model that did not have significantly better fit than a more restricted model. Therefore, the evidence can only be regarded as tentative. Nevertheless, it may be worth investigating processes that may generate the inverse relationship between 'changing aspects of work activities to express affect' and perceived performance. For example, the relationship may reflect the diversion of cognitive resources away from processing information relevant to performance, so that cognitive resources can be devoted to affect regulation (Beal et al., 2003).

There is evidence that writing or talking alone about affective experiences can enhance well-being (Lepore et al., 2000; Pennebaker, 1989, 1997). Therefore, the relationship between 'changing aspects of work activities to express affect' and other outcomes may be moderated by the extent to which people engage in deliberately reflective processes when using job control to express affect. Even so, the cognitive benefits of affective expression appear to be accentuated in the presence of support from others (Lepore et al., 2000). Implications for practice

One practical implication of the present study is that organizations should enable workers to exercise some control over work so that they are able to find suitable moments to express affect to others. Workers may need to be encouraged not only to use control over work to express affect at the appropriate time, but also to take time to find the most appropriate person to express affect to and an appropriate place to do so (Bamberger, 2009). Workers may also need to be encouraged to mutually construct a narrative of affect inducing events (Lepore et al., 2000) and to express pleasant affect as well as unpleasant affect when 
discussing negative events (Zellars \& Perrewé, 2001). Encouragement and knowledge of how best to express affect may be imparted through training or socialization processes. Once workers start expressing affect to others, trust and quality of relationships may develop into gain spirals (Halbesleben \& Wheeler, in press; Rimé, 2009).

\section{Strengths, limitations, and methodological implications}

One of the strengths of the present study is the measurement precision afforded by hourly assessments taken up to four times per day over five working days. The analyses also controlled for whether the hour's most salient affective event was pleasant interaction with others or helpful interactions with others. Including these control variables renders it unlikely that the relationships between TAL-EA and other variables could solely be attributed to social contact or other forms of support. Moreover, because associations between TAL-EA and the two mediators (understanding personal goals and perceived empathy) were also significant in the estimation of the fully saturated model (Model 1) that controlled for the effects of CHA-EA, the results indicate it is the social expression of affect that may confer benefits rather than affective expression through another means.

Participants were asked to choose from pre-defined lists the hour's most salient event and affective responses to that event. Although we allowed participants to endorse an 'other' option, the defined options presented to participants covered $79.0 \%$ and $83.7 \%$ of the events and affective reactions to events respectively. However, because participants responded at the same set times on each day, it is not clear if the 'other' option would have been endorsed more frequently at other times of the day. We did not assess the magnitude of the impact of the hour's most salient event on the individual. However, to some extent, the impact of an event is likely to be related to that event's influence on salient work goals (Lazarus, 1999). In the present study, we did assess attainment of two salient work goals (perceived performance, relationship quality) and personal understanding of goals. Moreover, our analyses controlled 
for inter-dependencies between affective well-being, perceived performance, and relationship quality. In sum, any potential influence of the events' impact on the results is mitigated because the options covered the majority of events and reactions to events at the times sampled, and we also assessed and controlled for goal related phenomena. Also, our hypotheses were not conditional on the types of events experienced or the affective reactions solicited by those events. Finally, the results from the instrumental variable analyses indicate it is unlikely that unmeasured variables (e.g., unclassified event type, event's impact) could account for the findings.

Bolger, Davis, and Rafaeli (2003) indicated that repeated sampling in quantitative diary studies is unlikely to alter the phenomena of interest. However, participants may habituate to repeated questions and variability in responses may decrease over time. If habituation were a problem, we would expect the variation in responses across the week to reduce. Therefore, we calculated correlations between the standard deviation in responses at each given measurement occasion and the rank of each measurement occasion in the series of occasions across the week (ranging from 1-20). We calculated these correlations for all the independent and criterion variables. If habituation were to be a problem, we would expect a negative correlation between the standard deviation of measures and the rank order of the measurement occasions. The range of correlations varied from $r=-.03$ to $r=.39$ (all $p>.10$ ), with an average of $r=.18$. Therefore, we found no evidence for habituation. Moreover, because we centered the data at each participant's mean, we analyzed within-person variability only. Habituated responding would serve to restrict within-person variability as fewer observations would deviate substantially from a person's mean. Habituated responding would thus reduce statistical power and bias the data against finding significant associations.

Person-mean centering also controls for stable between-person differences (e.g., attributable to trait affect, generally good understanding of personal goals). However, person- 
mean centering implies that any variance explained is within-person. In the present study, within-person centering is appropriate because the use of job resources for affect regulation is dynamic, there is substantial within-person variance in the criterion variables, and withinperson variance is itself theoretically meaningful (Xanthopoulou, Bakker, \& Ilies, 2012). Moreover, the substantive relationships found in the present study were replicated in supplementary analyses in which variables were centered at the grand mean (details available from authors).

Although the sample size is not atypical of experience sampling studies in work organizations (Ohly, Sonnentag, Niessen, \& Zapf, 2010), the nature of the sample may limit generalizability to other contexts. However, experience sampling methods have high ecological validity which provides some mitigation against the issue of generalizability (Bolger et al., 2003). A small sample size can cause problems of statistical power. In the present study, power was not an issue because the unit of analysis was the hourly assessment $(k=272)$ and not simply the sample size $(N=39$, Snijders \& Bosker, 1993).

We examined cross-sectional relationships with hourly data only. However, there are several factors which lend credibility to our interpretation of the findings. First, we included a range of design features that would render it unlikely that common method variance could account for the relationships observed in the present study. The design features included: the greater accuracy of measurement afforded by electronic ESM, variation in response formats for the assessments, and inclusion of a range of control variables (Podsakoff, MacKenzie, \& Podsakoff, 2012). Second, we examined models which allowed for other plausible explanations for the findings and the results from these models indicated that the most plausible explanation for the findings was that embedded in the Hypotheses. Third, in respect of analyses involving affective well-being, we built in an element of temporal priority: We used a measure of momentary (end of hour) affective well-being, but assessed affective 
expression and the mediators with reports over the previous hour. Moreover, because there were no significant direct relationships between either TAL-EA or CHA-EA and end of hour affect, it is unlikely the results reflect contamination between the affects expressed in the previous hour and affective well-being experienced at the end of the hour.

Nevertheless, it would be imprudent to conclude our results demonstrate causality. Rather, researchers may wish to consider using intervention and experimental studies to investigate further the relationships demonstrated in the present study, and more generally study the enactment of job resources for self-regulation. Researchers may also wish to explore other methods that might capture the intended purposes for which workers enact their work environment (e.g., ethnographic and other qualitative methods).

\section{Conclusions}

Although, the benefits of affective expression may accrue primarily through the elicitation of social support, the present study does indicate that job control may be used to obtain access to the social support necessary to accrue benefits from affective expression. The findings extend resource based models of job design from focusing on affective or goalrelated outcomes to also include benefits such as perceived empathy and relationship quality. The findings reinforce the importance of investigating not just the availability of job resources, but also the purposes for which job resources are enacted and co-dependence between how job resources are used. Because workers use job resources to express affect on a daily basis, the findings also lend credence to explanations of the relationship between work and well-being that are based on workers actively interpreting and acting on their work environment to regulate well-being on a dynamic and short-term basis. 


\section{References}

Ashforth, B. E., \& Humphrey, R. H. (1993). Emotional labor in service roles: The influence of identity. Academy of Management Review, 18, 88-115.DOI: 10.5465/AMR.1993.3997.

Ashforth, B.E., \& Humphrey, R.H. (1995). Emotion in the workplace: A reappraisal. Human Relations, 48, 97-125. DOI: 10.1177/0018726795.

Austenfeld, J.L., \& Stanton, A.L. (2004). Coping through emotional approach: A new look at emotion, coping, and health-related outcomes. Journal of Personality, 72, 1335-1363. DOI: 10.1111/j.1467-6494.2004.00299.x.

Baker, J.P., \& Berenbaum. H. (2007). Emotional approach and problem-focused coping: A comparison of potentially adaptive coping strategies. Cognition and Emotion, 21, 95-118. DOI: 10.1080/02699930600562276.

Bakker, A. B., \& Demerouti, E. (2007). The job demands-resources model: State of the art. Journal of Managerial Psychology, 22, 309-328. DOI:10.1108/02683940710733115.

Bakker, A. B., Demerouti, E., \& Sanz-Vergel, A. I. (2014). Burnout and work engagement: The JD-R approach. Annual Review of Organizational Psychology and Organizational Behavior, 1, 389-411.DOI: 10.1146/annurev-orgpsych-031413-091235.

Bamberger, P., (2009). Employee help-seeking: Antecedents, consequences, and new insights for future research. Research in Personnel and Human Resources Management, 28: 49-98. DOI:10.1108/S0742-7301(2009)0000028005.

Baumeister, R. F., \& Alquist, J. L. (2009). Self-regulation as a limited resource: Strength model of control and depletion. In Forgas, J.P., Baumeister R F., \& Tice D.M. (Eds.), Psychology of self-regulation: Cognitive, affective, and motivational processes. New York, NY: Psychology Press (21-33). 
Beal, D.J., Weiss, H.M., Barros, E., \& MacDermid, S.M. (2005). An episodic process model of affective influences on performance. Journal of Applied Psychology, 90, 1054-1068. DOI: 10.1037/0021-9010.90.6.1054.

Beck, N. (2008). Time-series-cross-section methods. In Oxford Handbook of Political Methodology. Oxford: Oxford Handbooks (475-493).

Berg, J. M., Grant, A. M., \& Johnson, V. (2010). When callings are calling: Crafting work and leisure in pursuit of unanswered occupational callings. Organization Science, 21, 973994. DOI: $10.1287 /$ orsc. 1090.0497.

Bolger, N., Davis, A., \& Rafaeli, E. (2003). Diary methods: Capturing life as it is lived. Annual Review of Psychology, 54, 579-616. DOI: 10.1146/annurev.psych.54.101601. 145030.

Breaugh, J.A. (1985). The measurement of work autonomy. Human Relations, 38, 551-570. DOI: $10.1177 / 001872678503800604$.

Butler, E.A., Egloff, B., Wilhelm, F.H., Smith. N.C., Erickson, E.A., \& Gross, J.J. (2003). The social consequences of expressive suppression. Emotion, 3, 48-67. DOI: 10.1037/15283542.3.1.48.

Byrne, B.M. (2012). Structural equation modeling with Mplus: Basic concepts, applications, and programming. New York: Routledge.

Carver, C.S., \& Scheier, M.F. (1990). Origins and functions of positive and negative affect: a control-process view. Psychological Review, 97, 19-35. DOI: 10.1037/0033295X.97.1.19.

Clark. M.S., \& Finkel, E.J. (2004). Does expressing emotion promote well-being? It depends on relationship context. In Tiedens, L.Z., \& Leach, C.W. (Eds.), The social life of emotions. Cambridge, England: Cambridge University Press (105-126). 
Côté, S. (2005). A social interaction model of the effects of emotion regulation on work strain. Academy of Management Review, 30, 509-530. DOI: 10.5465/AMR.2005.17293692.

Coupland, C., Brown, A.D, Daniels, K., \& Humphreys, M. (2008). Saying it with feeling: analysing speakable emotions. Human Relations, 61, 327-353. DOI: 10.1177/ 0018726708088997.

Curci, A., \& Bellelli, G. (2004). Cognitive and social consequences of exposure to emotional narratives: Two studies on secondary social sharing of emotions. Cognition and Emotion, 18, 881-900. DOI: 10.1080/02699930341000347.

Daniels, K. (2000). Measures of five aspects of affective well-being at work. Human Relations, $53,275-294$.

Daniels, K. (2006). Rethinking job characteristics in work stress research. Human Relations, 59, 267-290. DOI: 110.1177/0018726706064171.

Daniels, K. (2011). Stress and well-being are still issues and something still needs to be done: Or why agency and interpretation are important for policy and practice. In Hodgkinson, G.P., and Ford, J.K. (Eds.), International Review of Industrial and Organizational Psychology (Vol. 25). Chichester: Wiley (1-46).

Daniels, K., Beesley, N.J., Cheyne, A.J.T., \& Wimalasiri, V.P. (2008). Coping processes linking the Demands-Control-Support model, affect, and risky decisions at work. Human Relations, 61, 845-874. DOI: 10.1177/0018726708093543

Daniels, K., Beesley, N.J., Wimalasiri, V.P., Cheyne, A.J.T. (2013b). Problem-solving and well-being: Exploring the instrumental role of job control and social support. Journal of Management. DOI: 10.1177/0149206311430262.

Daniels, K., Boocock, G., Glover, J., Hartley, R., \& Holland, J. (2009). An experience sampling study of learning, affect, and the Demands Control Support model. Journal of Applied Psychology, 94, 1003-1017. DOI: 10.1037/a0015517. 
Daniels, K., Glover J., Beesley, N., Wimalisiri, V., Cohen, L., Cheyne, A., Hislop D. (2013a). Utilizing job resources: Qualitative evidence of the roles of job control and social support in problem solving. Work \& Stress, 27, 200-221. DOI: 10.1080/02678373.2013.792471.

Daniels, K., Wimalisiri, V.P., Cheyne, A.J.T., \& Story, V. (2011). Linking the Demands-ControlSupport Model to innovation: The moderating role of personal initiative on the generation and implementation of ideas. Journal of Occupational and Organizational Psychology. 84: 581-598. DOI: 10.1348/096317910X494269.

Demerouti, E., Bakker, A.B., Nachreiner, F., \& Schaufeli, W.B. (2001). The job demandsresources model of burnout. Journal of Applied Psychology, 86, 499-512. DOI: 10.1037/0021-9010.86.3.499.

De Waal, F.B. (2008). Putting the altruism back into altruism: the evolution of empathy. Annual Review of Psychology, 59, 279-300. DOI: 10.1146/annurev.psych. 59.103006 .093625$.

Diener, E., \& Larsen, R.J. (1993). The experience of emotional well-being. In Lewis, M. \& Havilland, J.M. (Eds.), Handbook of emotions. New York: Guildford Press (405-415).

Edwards, J. R., \& Lambert, L. S. (2007). Methods for integrating moderation and mediation: a general analytical framework using moderated path analysis. Psychological Methods, 12, 1-22. DOI: 10.1037/1082-989X.12.1.1.

Eisenberg, N. (2000). Emotion, regulation, and moral development. Annual Review of Psychology, 51, 665-697. DOI: 10.1146/annurev.psych.51.1.665.

Fischer, A.H., \& Manstead, A.S.R. (2008). Social functions of emotion. In Lewis, M., Haviland-Jones, J.M., \& Feldman-Barrett, L. (Eds.), Handbook of emotions $3^{\text {rd }}$ Ed. New York: Guildford (456-471).

Gable, S. L., Reis, H. T., Impett, E. A., \& Asher, E. R. (2004). What do you do when things go right? The intrapersonal and interpersonal benefits of sharing positive events. 
Journal of Personality and Social Psychology, 87, 228. DOI: 10.1037/00223514.87.2.228

Gorgievski, M. J., Halbesleben, J. R. B., \& Bakker, A. B. (2011). Expanding the boundaries of psychological resource theories. Journal of Occupational and Organizational Psychology, 84, 1-7. DOI: 10.1111/j.2044-8325.2010.02015.x.

Graham, S. M., Huang, J. Y., Clark, M. S., \& Helgeson, V. S. (2008). The positives of negative emotions: Willingness to express negative emotions promotes relationships. Personality and Social Psychology Bulletin, 34, 394-406. DOI: 10.1177/ 0146167207311281.

Grant, A. M. (2007). Relational job design and the motivation to make a prosocial difference. Academy of Management Review, 32, 393-417. DOI: 10.5465/AMR.2007.24351328.

Grant, A.M., \& Parker, S.K. (2009). Redesigning work design theories: The rise of relational and proactive perspectives. Academy of Management Annals, 3, 317-375. DOI: $10.1080 / 19416520903047327$.

Gross, J.J. (2008). Emotion regulation. In Lewis, M., Haviland-Jones, J.M., \& FeldmanBarrett, L. (Eds.), Handbook of Emotions (3rd Ed.). New York: Guildford (497-513). Gross, J.J., \& Thompson, R.A. (2007). Emotional regulation: conceptual foundations. In J.J. Gross (Ed.), Handbook of emotional regulation. New York: Guilford.

Halbesleben, J. R., \& Wheeler, A. R. (in press). To invest or not? The role of coworker support and trust in daily reciprocal gain spirals of helping behavior. Journal of Management. DOI: 10.1177/0149206312455246.

Häusser, J.A., Mojzisch, A., Niesel, M., \& Schulz-Hardt, S. (2010). Ten years on: A review of recent research on the Job-Demand-Control(-Support) model and psychological well-being. Work \& Stress, 24, 1-35. DOI: 10.1080/02678371003683747 
Hobfoll, S.E. (2002). Social and psychological resources and adaptation. Review of General Psychology, 6, 307-324. DOI: 10.1037/1089-2680.6.4.307.

Ilies, R., Dimotakis, N., \& De Pater, I.E. (2010). Psychological and physiological reactions to high workloads: Implications for well-being. Personnel Psychology, 63, 407-436. DOI: 10.1111/j.1744-6570.2010.01175.x.

Ilies, R., Keeney, J., \& Scott, B. A. (2011). Work-family interpersonal capitalization: Sharing positive work events at home. Organizational Behavior and Human Decision Processes, 114, 115-126. DOI: 10.1016/j.obhdp.2010.10.008.

Karasek, R.A., \& Theorell, T. (1990). Healthy work. New York: Basic Books.

Lazarus, R.S. (1999). Stress and emotion: A new synthesis. New York: Springer.

Leana, C., Appelbaum, E., \& Sevchuk, I. (2009). Work process and quality of care in early childhood education: The role of job crafting. Academy of Management Journal, 52, 1169-1192. DOI: 10.5465/AMJ.2009.47084651.

Lepore, S.J., Ragan, J.D., \& Jones, S. (2000). Talking facilitates cognitive-emotional processes of adaptation to an acute stressor. Journal of Personality and Social Psychology, 78, 499508. DOI: 10.1037/0022-3514.78.3.499.

Locke, E. A., \& Latham, G. P. (2002). Building a practically useful theory of goal setting and task motivation: A 35-year odyssey. American Psychologist, 57, 705-717. DOI: 10.1037//0003-066X.57.9.705.

MacKinnon, D. P., Fritz, M. S., Williams, J., \& Lockwood, C. M. (2007). Distribution of the product confidence limits for the indirect effect: Program PRODCLIN. Behavior Research Methods, 39, 384-389. DOI: 10.3758/BF03193007.

Mauss, I. B., Shallcross, A. J., Troy, A. S., John, O. P., Ferrer, E., Wilhelm, F. H., \& Gross, J. J. (2011). Don't hide your happiness! Positive emotion dissociation, social 
connectedness, and psychological functioning. Journal of Personality and Social Psychology, 100, 738-748. DOI: 10.1037/a0022410.

Muthén, B. (1997). Latent variable modeling of longitudinal and multilevel data. Sociological Methodology, 27, 453-481. DOI: 10.1111/1467-9531.271034.

Muthén, L.K. \& Muthén, B.O. (1998-2012). Mplus User's Guide. Seventh Edition. Los Angeles, CA: Muthén \& Muthén

Ohly, S., Sonnentag, S., Niessen, C., \& Zapf, D. (2010). Diary studies in organizational research: An introduction and some practical recommendations. Journal of Personnel Psychology, 9: 79-93. DOI: 10.1027/1866-5888/a000009

Oldham, G. R., \& Rotchford, N. L. (1983). Relationships between office characteristics and employee reactions: A study of the physical environment. Administrative Science Quarterly, 28, 542-556.

Parkinson, B., \& Totterdell, P. (1999). Classifying affect-regulation strategies. Cognition \& Emotion, 13, 277-303. DOI: 10.1080/026999399379285.

Pennebaker, J. W. (1989). Confession, inhibition, and disease. In L. Berkowitz (Ed.), Advances in experimental social psychology (Vol. 22). Orlando, FL: Academic Press $(211-244)$

Pennebaker, J. W. (1997). Writing about emotional experiences as a therapeutic process. Psychological Science, 8, 162-166. DOI: 10.1111/j.1467-9280.1997.tb00403.x.

Petrou, P., Demerouti, E., Peeters, M. C., Schaufeli, W. B., \& Hetland, J. (2012). Crafting a job on a daily basis: Contextual correlates and the link to work engagement. Journal of Organizational Behavior, 33, 1120-1141. DOI: 10.1002/job.1783.

Podsakoff, P.M., MacKenzie, S.B., Lee, J.Y., \& Podsakoff, N.P. 2003. Common method biases in behavioral research: A critical review of the literature and recommended remedies. Journal of Applied Psychology, 88: 879-903. DOI: 10.1037/0021-9010.88.5.879. 
Preacher, K. J., \& Selig, J. P. (2012). Advantages of Monte Carlo confidence intervals for indirect effects. Communication Methods and Measures, 6, 77-98. DOI: 10.1080/ 19312458.2012.679848.

Rimé, B. (2007). Interpersonal emotion regulation. In J.J. Gross (Ed.), Handbook of emotional regulation. New York: Guilford (466-485).

Rimé, B. (2009). Emotions elicit the social sharing of emotion: Theory and empirical review. Emotion Review, 1, 60-85. DOI: 10.1177/1754073908097189.

Rimé, B., Philippot, P., Boca, S., \& Mesquita, B. (1992). Long-lasting cognitive and social consequences of emotion: Social sharing and rumination. In W. Stroebe \& M. Hewstone (Eds.), European review of social psychology (Vol. 3). Chichester: Wiley (225-258). DOI: 10.1080/14792779243000078.

Ryan, R.M. (1995). Psychological needs and the facilitation of integrative processes. Journal of Personality, 63, 432-444. DOI: 10.1111/j.1467-6494.1995.tb00501.x.

Satorra, A. (1992). Asymptotic robust inferences in the analysis of mean and covariance structures. Sociological Methodology, 22, 249-278. DOI: 10.2307/270998.

Shaver, J. M. (2005). Testing for mediating variables in management research: concerns, implications, and alternative strategies. Journal of Management, 31, 330-353. DOI: $10.1177 / 0149206304272149$.

Skinner, E.A., Edge, K., Altman, J., \& Sherwood, H. (2003). Searching for the structure of coping: a review and critique of category systems for classifying ways of coping. Psychological Bulletin, 129, 216-269. DOI: 10.1037/0033-2909.129.2.216.

Snijders, T., \& Bosker, R. (1999). Multilevel analysis: An introduction to basic and advanced multilevel modeling. Thousand Oaks, CA: Sage. 
Stanton, A.L., \& Franz, R. (1999). Focusing on emotion: an adaptive coping strategy? In Snyder, C.R. (Ed.), Coping: The psychology of what works. New York: Oxford University Press (90-118).

Tims, M., Bakker, A. B., \& Derks, D. (2013). The impact of job crafting on job demands, job resources, and well-being. Journal of Occupational Health Psychology, 18, 230-240. DOI: $10.1037 / \mathrm{a} 0032141$.

Tims, M., Bakker, A. B., Derks, D., \& van Rhenen, W. (in press). Job crafting at the team and individual level: Implications for work engagement and performance. Group \& Organization Management. DOI: 10.1177/1059601113492421.

Todd, M., Tennen, H., Carney, M.A., Armeli, S., \& Affleck, G. Do we know how we cope? Relating daily coping reports to global and time-limited retrospective assessments. Journal of Personality and Social Psychology, 2004, 86, 310-319. DOI: 10.1037/0022-3514.86.2.310.

Trougakos, J. P., Beal, D. J., Green, S. G., \& Weiss, H. M. (2008). Making the break count: An episodic examination of recovery activities, emotional experiences, and positive affective displays. Academy of Management Journal, 51, 131-146. DOI: 10.5465/AMJ.2008.30764063.

Trougakos, J., Hideg, I., Cheng, B., \& Beal, D. (in press). Lunch breaks unpacked: The role of autonomy as a moderator or recovery during lunch. Academy of Management Journal. doi:10.5465/amj.2011.1072. DOI: 10.5465/amj.2011.1072.

Van den Broeck, A., Vansteenkiste, M., De Witte, H., \& Lens, W. (2008). Explaining the relationships between job characteristics, burnout, and engagement: The role of basic psychological need satisfaction. Work \& Stress, 22, 277_294. DOI: $10.1080 / 02678370802393672$. 
Van Kleef, G. A. (2009). How Emotions Regulate Social Life The Emotions as Social Information (EASI) Model. Current Directions in Psychological Science, 18, 184-188. DOI: $110.1111 / \mathrm{j} .1467-8721.2009 .01633 . x$.

Van Veldhoven, M., Taris, T. W., de Jonge, J., \& Broersen, S. (2005). The relationship between work characteristics and employee health and well-being: how much complexity do we really need? International Journal of Stress Management, 12, 3-28. DOI: 10.1037/10725245.12.1.3.

Vohs, K.D., \& Baumeister, R.F. (2004). Understanding self-regulation: An introduction. In Baumeister, R.F. \& Vohs, K.D. (Eds.) Handbook of self-regulation. New York: Guildford $(1-9)$.

Wall, T.D., Jackson, P.R., Mullarkey, S., \& Parker, S. (1996). The demands-control model of job strain: A more specific test. Journal of Occupational and Organizational Psychology, 69, 153-166. DOI: 10.1111/j.2044-8325.1996.tb00607.x.

Warr, P. (2007). Work, happiness and unhappiness. Mahwah, NJ: Erlbaum.

Weick, K.E. (1995). Sensemaking in organizations. Thousand Oaks CA: Sage.

Weiss, H.M., \& Cropanzano, R. (1996). Affective events theory: A theoretical discussion of the structure, causes, and consequences of affective experiences at work. In B.M. Staw \& L.L. Cummings (Eds.), Research in organizational behavior, (Vol. XVIII). Greenwich CT: JAI Press (1-74).

Wrzesniewski, A., \& Dutton, J. (2001). Crafting a job: Revisioning employees as active crafters of their work. Academy of Management Review, 26, 179-201. DOI: 10.2307/259118.

Xanthopoulou, D., Bakker, A.B., Demerouti, E., Schaufeli, W.B. (2009). Work engagement and financial returns: A diary study on the role of job and personal resources. Journal of 
Occupational and Organizational Psychology, 82, 183-200. DOI: 10.1348/ $096317908 X 285633$.

Xanthopoulou, D., Bakker, A. B., \& Ilies, R. (2012). Everyday working life: Explaining within-person fluctuations in employee well-being. Human Relations, 65, 1051-1069. DOI: $10.1177 / 0018726712451283$.

Zellars, K.L., \& Perrewé, P.L. (2001). Affective personality and the content of emotional support: Coping in organizations. Journal of Applied Psychology, 86, 459-467. DOI: 10.1037/ 0021-9010.86.3.459. 


\section{Footnotes}

${ }^{1}$ In most circumstances, centering at a person's mean would remove all between-person variance, and return ICCs of zero. In the present study, we calculated the mean from each participant's complete set of data, regardless of whether a particular datum had a lagged score from the previous time period or not. Using the complete set of data represents a more accurate estimate of each participant's mean. However, because of missing observations from some time periods, more data were used to calculate each person's mean than the data used in the analyses that included lagged scores. This resulted in slight deviations from zero as the average for each variable in the within-person analyses. In these circumstances, checking ICCs indicates whether there are dependencies in the data introduced because of missing observations. Centering all variables at the person's mean also enabled us to estimate residual correlations to reflect withinperson processes, rather than confounding residual correlations with between-person variance. ${ }^{2}$ Although not shown in Figure 1, Model 3 also indicated that CHA-EA at the previous measurement occasion was related to TAL-EA $(B=0.17, p<.05)$, but TAL-EA at previous measurement occasion was not related to CHA-EA. These results lend further support to the reasoning underpinning Hypothesis 1 that CHA-EA may be an influence on TAL-EA. There was no other instance of a significant association between a criterion variable and a hypothesized independent variable assessed at the previous measurement occasion. 
Table 1

Means, standard deviations, reliabilities, and within-person correlations

\begin{tabular}{|c|c|c|c|c|c|c|c|c|c|c|c|c|c|c|c|c|c|}
\hline & Mean & $S D$ & 1. & 2. & 3. & 4. & 5. & 6. & 7. & 8. & 9. & 10. & 11. & 12. & 13. & 14. & 15 . \\
\hline 1. End of hour NA & 2.24 & 1.17 & .85 & & & & & & & & & & & & & & \\
\hline 2. End of hour PA & 2.77 & 1.31 & $-.38^{* *}$ & .96 & & & & & & & & & & & & & \\
\hline 3. Perceived performance & 3.39 & 1.15 & $-.41^{* *}$ & $.47^{*} *$ & .90 & & & & & & & & & & & & \\
\hline 4. Relationship quality & 3.41 & 1.05 & $-.37^{* *}$ & $.37^{* *}$ & $.56^{* *}$ & .78 & & & & & & & & & & & \\
\hline 5. Understanding goals & 2.72 & 1.17 & $-.26^{* *}$ & .39 & .40 & .39 & .84 & & & & & & & & & & \\
\hline 6. Perceived empathy & 3.17 & 1.13 & $-.24^{* *}$ & $.36^{* *}$ & $.32^{* *}$ & $.44^{* *}$ & $.39^{* *}$ & .86 & & & & & & & & & \\
\hline 7. Event - conflict & -- & -- & $.18^{* * *}$ & $-.18^{* *}$ & -.10 & $-.25^{* *}$ & .03 & $-.14^{* *}$ & -- & & & & & & & & \\
\hline 8. Event - Pleasant interaction & -- & -- & $-.23^{* *}$ & $.26^{* *}$ & $.25^{* *}$ & $.28^{* *}$ & $.13^{* *}$ & $.15^{* *}$ & $-.15^{* *}$ & -- & & & & & & & \\
\hline 9. Event - barriers to tasks & -- & -- & $.30^{* *}$ & $-.22^{* *}$ & $-.35^{* *}$ & $-.18^{* *}$ & $-.12 *$ & -.07 & $-.13^{* *}$ & $-.36^{* *}$ & -- & & & & & & \\
\hline 10. Event - receiving help & -- & -- & -.04 & .09 & .07 & .04 & .06 & -.03 & -.08 & $-.18^{* *}$ & $-.16^{* *}$ & -- & & & & & \\
\hline 11. Event - difficult work & -- & -- & -.01 & -.03 & .03 & .03 & -.02 & -.05 & $-.18^{* *}$ & $-.22^{* *}$ & $-.23^{* *}$ & -.08 & -- & & & & \\
\hline 12. Event - unpleasant affect & -- & -- & $.49^{* *}$ & $-.42^{* *}$ & $-.43^{* *}$ & $-.33^{* *}$ & $-.18^{* *}$ & $-.20^{* *}$ & $.27^{* *}$ & $-.47^{* *}$ & $.44^{* *}$ & -.06 & $.12^{*}$ & -- & & & \\
\hline 13. Event -pleasant affect & -- & -- & $-.38^{* *}$ & $.44^{* *}$ & $.40^{* *}$ & $.36^{* *}$ & $.24^{* *}$ & $.19^{* *}$ & $-.18^{* *}$ & $.58^{* *}$ & $-.38^{* *}$ & .07 & -.03 & $-.71^{* *}$ & -- & & \\
\hline 14. CHA-EA & 2.00 & 1.24 & $.11^{*}$ & .02 & $-.13^{*}$ & -.01 & $.10^{*}$ & .05 & .05 & -.02 & $12^{*}$ & -.01 & -.04 & .08 & -.02 & .82 & \\
\hline 15. TAL-EA & 2.17 & 1.37 & .02 & $.13^{* *}$ & .08 & $.14^{* *}$ & $.11^{*}$ & $.27^{* *}$ & -.01 & $.12^{* *}$ & $.10^{*}$ & -.06 & -.06 & .05 & .04 & $.46^{* *}$ & .88 \\
\hline
\end{tabular}

$\mathrm{n}=39$, no. observations $=461 .^{*} p<.05,{ }^{* * *} p<.01$.

All correlations are based on variables centered at each participant's mean. Reliabilities (Cronbach's alpha) shown on primary diagonal. TALEA is 'talking to others to express affect', CHA-EA is 'changing aspects of work activities to express affect'. 
Figure Captions

Figure 1. Summary of best fitting model. 


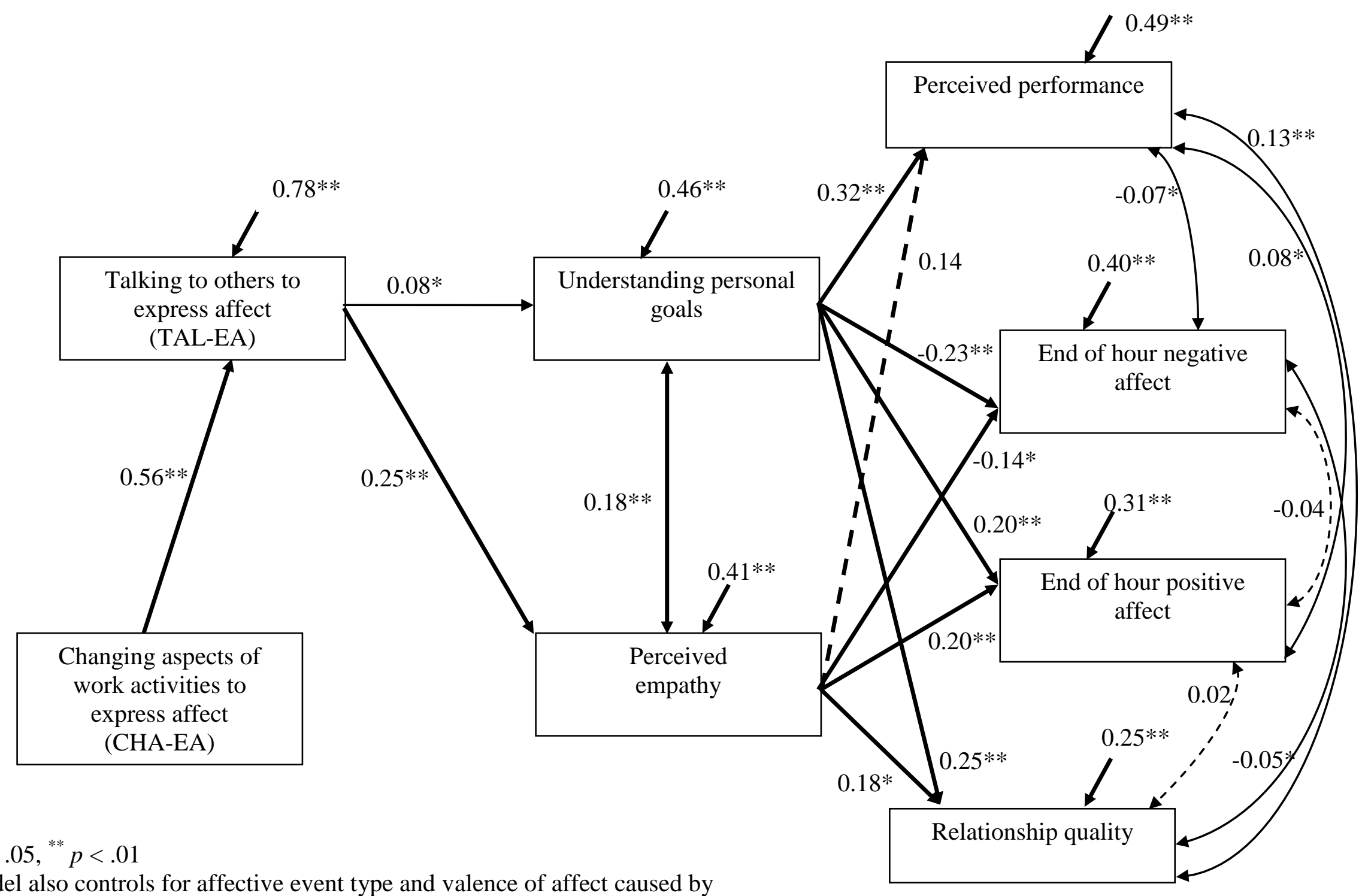

Model also controls for affective event type and valence of affect caused by affective event, and values of criterion and independent variables at previous measurement occasion. Full details available from authors 